\title{
A demonstration of persistent human avoidance in extinction
}

\author{
RICHARD W. WILLIAMS and DONALD J. LEVIS \\ State University of New York, Binghamton, New York
}

\begin{abstract}
The present study provides a replication of Malloy and Levis's (1988) finding of persistent human avoidance responding during extinction. Forty-seven percent of the subjects who learned failed to extinguish by Trial 500. This result was of particular interest given that the extreme avoidance persistence was obtained in many cases with only one CS-UCS (shock) pairing and with a relatively mild UCS (2.5-mA shock level). A comparison between extinguishers and nonextinguishers suggested that the traditional laws of extinction were operating in both groups. These data parallel those found with infrahumans suggesting the governance of comparable conditioning principles. The theoretical importance of these findings are discussed.
\end{abstract}

Attempts by learning theorists to extend established laboratory principles of fear-avoidance conditioning and conflict learning to explain the development, maintenance, and unlearning of human psychological symptoms have resulted in important and influential contributions (e.g., Dollard \& Miller, 1950; Eysenck, 1979; Levis, 1985; Mowrer, 1950; Reiss \& Bootzin, 1985; Stampfl \& Levis, 1967; Wolpe, 1958). In the 1970s, a number of critics challenged the viability of a traditional learning approach to account for the persistence of human symptoms, which sometimes last for years (e.g., Gray, 1971; Kimmel, 1971; Rachman, 1976; Seligman \& Johnston, 1973). The main argument advanced was that laboratory demonstrations of extreme persistence of avoidance and fear responding in extinction were rare. Mackintosh (1974), in reviewing the avoidance area, confirmed the critics observations that in most cases infrahuman avoidance extinction, as well as fear extinction, is relatively short lived. Extinction of both responses typically occurs within 20 to 40 trials; rarely does this process require more than 100 trials.

Although Mackintosh's (1974) conclusions accurately reflected the literature as a whole, more studies than he reported demonstrating persistent avoidance responding in extinction existed at that time (Baker, 1968; Denny, 1971; Kostanek \& Sawrey, 1965; Levis, 1966; Levis, Bouska, Eron, \& Mcllhon, 1970; Oliverio, 1967; Seligman \& Campbell, 1965; Solomon \& Wynne, 1953; Solomon, Kamin, \& Wynne, 1953). Since that time additional studies can be added to the list (e.g., Levis \& Boyd, 1979; McAllister, McAllister, Scoles, \& Hampton, 1986; Stampfl, 1987). To date, infrahuman examples of extreme resistance to extinction of both fear and avoidance responding cannot be considered to be rare with the procedural methods and principles responsible for producing the effect clearly delineated (see Levis, 1989).

Reprint requests should be addressed to Donald J. Levis, Department of Psychology, SUNY Binghamton, Binghamton, NY 13901.
However, this issue is less clear when the human avoidance conditioning literature is reviewed. Prior to the publication of the Malloy and Levis (1988) study, we could not find one human study that showed substantial resistance to extinction of avoidance responding. Bank (1965) reported that after 80 acquisition trials the most persistent group avoided for a mean of only 36 trials. Meyer (1970) and Drake and Meyer (1972) found that, after 40 training trials, subjects extinguished within 47 and 25 trials, respectively (also see Maxwell, Miller, \& Meyer, 1971; Moffat \& Koch, 1974). However, the Levis (1971) and Levis and Levin (1972) data suggest that extreme resistance to extinction is possible. Although their group means for extinction trials ranged between 60 and 82 trials, many of their subjects reached the imposed 100 extinction trial limit without extinguishing. Malloy and Levis (1988) extended this limit to 500 trials and reported $42 \%$ of the subjects were still responding at this point.

Because this issue of extreme resistance to extinction is of central theoretical importance to both learning theory and applied behavioral theory, the present study was designed, in part, to provide a replication of the Malloy and Levis (1988) findings.

\section{METHOD}

\section{Subjects and Apparatus}

The subjects were 36 students ( 18 men, 18 women) from an introductory psychology course. They participated as one means of gaining research credit. The apparatus was identical to that reported in Malloy and Levis (1988; see Williams, 1986, for a more detailed presentation of the procedure and results).

\section{Procedure}

On Day 1, each subject received one classical conditioning trial consisting of a 1.0 -sec-duration CS (S1; light or time), followed by 0.5 sec-duration CS (S2), followed by a 2.5 -mA shock of 0.2 -sec duration to the subject's forearm. The subject was then instructed that the shock could be avoided by pulling a hand dynamometer (a response required a pull of at least $3 \mathrm{~kg}$ ) directly in front of him/her. Standard discrete avoidance learning trials began on the next trial. The ITI was randomized between 8 and $15 \mathrm{sec}$. The avoidance criterion for each subject was 10 
Table 1

Comparison Data: Extinguishers $(n=19)$ Versus Nonextinguishers $(n=17)$

\begin{tabular}{lcc}
\hline & Extinguishers & Nonextinguishers \\
\hline Mean Total Avoidance Trials (Day 2) & 138 & 497 \\
Mean Response Latency (sec) & & \\
$\quad$ First 10 Trials & .605 & .388 \\
$\quad$ Last 10 Trials & .814 & .486 \\
Mean Magnitude of Dynamometer Pull (kg) & & \\
$\quad$ First 10 Trials & 17.4 & 19.2 \\
$\quad$ Last 10 Trials & 11.5 & 13.6 \\
\hline
\end{tabular}

consecutive avoidance responses to $\mathrm{S} 1$. Electric shock was discontinued after five nonavoidance trials and a subject's participation was stopped if the learning criterion was not reached within 30 trials. Sixteen subjects did not meet this criterion and were replaced. For the subjects who met the avoidance criterion, the procedure was discontinued once the criterion was reached. Each subject was then scheduled to return within a 24- to 48-h period defined as Day 2 .

On Day 2, the subjects were divided into three groups and presented in a different, nonshock room one trial of $S 1, S 2$, or no CS. The original intent of this one-trial probe presentation was to evaluate whether this manipulation functions as a reactivation stimulus. The subjects were then returned to the conditioning room where the avoidance instructions given on Day 1 were readministered. Extinction trials were continued but only to $\mathrm{S} 1$. The subjects were discontinued if they either met an extinction criterion of five consecutive nonavoidable trials or reached Trial 500 (Williams, 1986).

\section{RESULTS AND DISCUSSION}

The acquisition data collected on Day 1 produced a combined mean of 1.5 shock trials, 11.6 avoidance trials, and .433 response latency. Twenty-two subjects received only one shock trial, the first classical conditioning trial. Analysis of the extinction data revealed an absence of any reliable effect from the one-trial probe stimulus. None of the analyses revealed any differences between male and female subjects. This lack of effect may be related, in part, to an obtained ceiling effect. Forty-seven percent of the subjects failed to extinguish by Trial 500 . The mean number of avoidance trials in extinction across subjects was 30. Table 1 divides the groups into extinguishers and nonextinguishers. The subjects who did not extinguish showed shorter response latencies across all blocks of trials and tended to have higher response magnitudes. The subjects who extinguished showed increased latencies and decreased magnitudes, as would be predicted by a strict extinction explanation. Importantly, the subjects who did not extinguish by Trial 500 were showing trends in the direction of extinction. It should be remembered that the extinction data only were obtained to S1, with S2 not presented. As Malloy and Levis's (1988) data suggest, the resilience to extinction effect in the present study would have been expected to be enhanced by the addition of S2. These data support the contention that persistent avoidance responding in extinction can be obtained in a laboratory setting for humans.

\section{REFERENCES}

BAKER, T. W. (1968). Properties of compound conditioned stimuli and their components. Psychological Bulletin, 70, 611-625.
BanKs, R. K. (1965). Effect of pairing a stimulus with presentations of the UCS on extinction of an avoidance response in humans. Journal of Experimental Psychology, 70, 294-299.

DENNY, M. R. (1971). Relaxation theory and experiments. In F. R. Brush (Ed.), Aversive conditioning and learning (pp. 235-295). New York: Academic Press.

Dollard, J., \& Miller, N. E. (1950). Personality and psychotherapy. New York: McGraw-Hill.

DRAKE, R., \& MEYER, P. A. (1972). Immediate generalized and enduring effectiveness of punishment and response prevention on human avoidance responding. Journal of Experimental Psychology, 96, 110-113.

EYSENCK, H. J. (1979). The conditioning model of neurosis. Behavioral \& Brain Sciences, 2, 155-166.

GraY, J. (1971). The psychology of fear and stress. London: Weidenfeld and Nicholson.

KIMMEL, H. D. (1971). Experimental psychopathology: Recent research and theory. New York: Academic Press.

Kostanek, D. J., \& SaWrey, J. M. (1965). Acquisition and extinction of shuttlebox avoidance with complex stimuli. Psychonomic Science, 3, 369-370.

LEVIS, D. J. (1966). Effects of serial CS presentation and other characteristics of the CS on the conditioned avoidance response. Psychological Reports, 18, 755-766.

LEVIS, D. J. (1971). Effects of serial CS presentation on a fingerwithdrawal avoidance response to shock. Journal of Experimental Psychology, 87, 71-77.

LEVIS, D. J. (1985). Implosive therapy: A comprehensive extension of conditioning theory of fear/anxiety to psychopathology. In S. Reiss \& R. R. Bootzin (Eds.), Theoretical issues in behavior therapy (pp. 4982). New York: Academic Press.

LEVIS, D. J. (1989). The case for a return to a two-factor theory of avoidance: The failure of non-fear interpretations. In S. D. Klein \& R. R. Mowrer (Eds.), Contemporary learning theories, Pavlovian conditioning and the status of traditional learning theory (pp. 227-277). Hillsdale, NJ: Erlbaum.

Levis, D. J., BousKa, S. A., Eron, J. B., \& Mcllhon, M. D. (1970). Serial CS presentation and one-way avoidance conditioning: A noticeable lack of delay in responding. Psychonomic Science, 20, 147-149.

LEVIS, D. J., \& BoYD, T. L. (1979). Symptom maintenance: An infrahuman analysis and extension of the conservation of anxiety principle. Journal of Abnormal Psychology, 88, 107-120.

LEVIS, D. J., \& LeVIN, H. S. (1972). Escape maintenance under serial and simultaneous compound presentation of separately established conditioned stimuli. Journal of Experimental Psychology, 95, 451-452.

MACKInTOSH, N. J. (1974). The psychology of animal learning. New York: Academic Press.

MALLOY, P., \& LeVIS, D. J. (1988). A laboratory demonstration of persistent human avoidance. Behavior Therapy, 19, 229-241.

Maxwell, W. A., Miller, F. D., \& Meyer, P. A. (1971). The relationship between punishment and unavoidability in eliminating avoidance behavior in humans. Psychonomic Science, 23, 435-436.

McAllister, W. R., McAllister, D. E., Scoles, M. T., \& HAMPTON, S. R. (1986). Persistence of fear-reducing behavior: Relevance for conditioning theory of neurosis. Journal of Abnormal Psychology, 93, 365-372.

MEYER, P. A. (1970). Role of an unavoidability procedure in eliminating avoidance behavior with humans. Journal of Experimental Psychology, 86, 337-340. 
Moffat, G. H., \& Косн, D. H. (1974). Effects of delay and duration of punished extinction following avoidance conditioning. Psychological Reports, 34, 779-784.

MOWRER, O. H. (1950). Learning theory and personality dynamics: Selected papers. New York: Ronald Press.

Oliverio, A. (1967). Effects of different conditioning schedules based on visual and acoustic conditioned stimulus on avoidance learning of two strains of mice. Journal of Psychology, 65, 131-139.

Rachman, S. (1976). The passing of the two-stage theory of fear and avoidance. Behavior Research \& Therapy, 7, 295-302.

ReIss, S., \& BootzIN, R. R. (1985). Theoretical issues in behavior therapy. New York: Academic Press.

Seligman, M. E. P., \& Campbell, B. A. (1965). Effects of intensity and duration of punishment on extinction of an avoidance response. Journal of Comparative \& Physiological Psychology, 59, 295-297.

Seligman, M. E. P., \& Johnston, J. C. (1973). A cognitive theory of avoidance learning. In F. J. McGuigan \& D. B. Lumsden (Eds.), Contemporary approaches to conditioning and learning. New York: Wiley.

Solomon, R. L., KAmin, L. J., \& WynNe, L. C. (1953). Traumatic avoidance learning: The outcomes of several extinction procedures with dogs. Journal of Abnormal \& Social Psychology, 48, 291-302.

Solomon, R. L., \& WYNNE, L. C. (1953). Traumatic avoidance learning: Acquisition in normal dogs. Psychological Monographs, 67(No. 354), 1-19.

STAMPFL, T. G. (1987). Theoretical implications of the neurotic paradox as a problem in behavior theory: An experimental resolution. Behavior Analyst, 10, 161-173.

Stampfl, T. G., Levis, D. J. (1967). The essentials of implosive therapy: A learning-theory based psychodynamic behavioral therapy. Journal of Abnormal Psychology, 72, 496-503.

WILLIAMs, R. W. (1986). The role of memory reactivation in the maintenance of human avoidance responding. Unpublished master's thesis, SUNY, Binghamton, NY.

WolPE, J. (1958). Psychotherapy by reciprocal inhibition. Stanford: Stanford University Press.

(Manuscript received August 3, 1990.) 